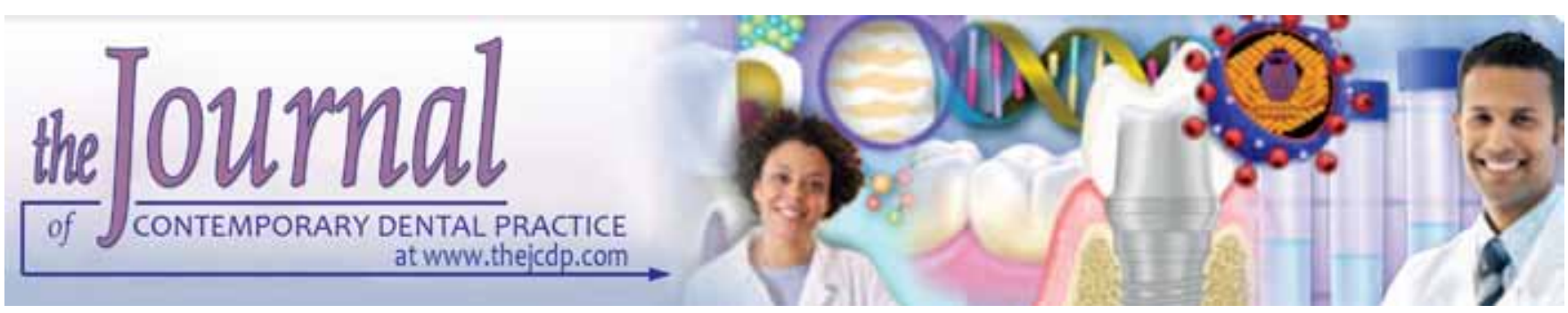

\title{
Nd:YAG Laser to obtain Irregularities on the Inner Surface of Porcelain
}

\author{
${ }^{1}$ Thiago Soares Porto, ${ }^{2}$ Betina Grehs Porto, ${ }^{3}$ Edson Alves de Campos, ${ }^{4}$ Sizenando de Toledo Porto-Neto \\ ${ }^{5}$ Monica Barros da Silva, ${ }^{6}$ Shilpa H Bhandi, ${ }^{7}$ Mateus Rodrigues Tonetto, ${ }^{8}$ Welingtom Dinelli \\ ${ }^{9}$ Mathéus Coelho Bandeca
}

\section{ABSTRACT}

Aim: The aim of this study was to evaluate the inner surface of two ceramic systems: IPS Empress II (Ivoclar Vivadent, Germany) and In-Ceram Alumina (Vita Zahnfabrick, Germany) submitted to surface treatments, especially by Nd:YAG laser.

Materials and methods: Fifty samples were prepared in pellet form for each ceramic system according to manufacturers' specifications. The samples were stored at room temperature and then be subjected to surface treatment: without treatment (T0) (control), hydrofluoric acid-etched (T1), hydrofluoric acidetched associated with the airborne particle-abraded (T2); CoJet system (T3), Nd:YAG laser (T4). The data were performed the statistical analysis by ANOVA and Tukey's test $(p<0.001)$

Results: The group control (T0) of the ceramics, the analysis showed the lowest roughness values; for the System Alumina In-Ceram, treatment with hydrofluoric acid (T1), associated with hydrofluoric acid and airborne particle-abraded (T2) and Nd:YAG laser (T4), had no statistically significant difference, whereas for the IPS Empress System II treatment with hydrofluoric acid (T1) and hydrofluoric acid associated with airborne particle-abraded (T2), had no statistically significant difference between the system and also CoJet (T3) and hydrofluoric acid associated with the airborne particle-abraded (T2). Photomicrographs of

\footnotetext{
1-4,8 Department of Restorative Dentistry, Universidade Estadual Paulista, Araraquara, São Paulo, Brazil

5,9 Department of Postgraduate Program in Dentistry, CEUMA University, São Luis, MA, Brazil

${ }^{6}$ Department of Conservative Dentistry and Endodontics, MS Ramaiah Dental College and Hospital, Bengaluru, Karnataka India

${ }^{7}$ Department of Dentistry, University of Cuiaba, Postgraduation in Integrated Sciences, Cuiaba, MT, Brazil
}

Corresponding Author: Mathéus Coelho Bandeca, Professor Department of Postgraduate Program in Dentistry, CEUMA University, Rua Josué Montello, s/n, Zip Code: 65.075-120 São Luis, MA, Brazil, e-mail: matheus.bandeca@utoronto.ca scanning electron microscopy showed different characteristics to the treatments for each ceramic system.

Conclusion: The IPS Empress II had the appearance of favoring the retention when treated with hydrofluoric acid, as well as its association with the airborne particle-abraded. Uncertainty in Alumina, treatment with hydrofluoric acid associated with the airborne particle-abraded and CoJet system and provided a surface with irregularities. With respect to the laser further studies should be performed for parameters that are ideal for your application.

Clinical relevance: The ceramic restorations are attractive due of their excellent esthetics and the ability to stay for long periods. However, the retention of ceramic requires further study.

Keywords: Ceramics, Laser, Scanning electron microscopy.

How to cite this article: Porto TS, Porto BG, de Campos EA, de Toledo Porto-Neto S, da Silva MB, Bhandi SH, Tonetto MR, Dinelli W, Bandeca MC. Nd:YAG Laser to obtain Irregularities on the Inner Surface of Porcelain. J Contemp Dent Pract 2015;16(6):451-457.

\section{Source of support: Nil}

Conflict of interest: None

\section{INTRODUCTION}

The dental ceramics are considered highly esthetic restorative materials with inherent properties that can better simulate the appearance of natural dentition. Other remarkable features include translucency, fluorescence, chemical stability, biocompatibility, high compressive strength and coefficient of thermal expansion similar dental structures. Despite numerous advantages, the ceramics are brittle under tensile loads and this fact can be attributed to the presence and propagation of microcracks in the material surface, which makes ceramic susceptible to fracture during the process of cementing and under occlusal loads. ${ }^{1}$ 
One way to improve retention of restorative materials to tooth structure is by obtaining irregularities by physical and chemical methods, such as airborne particle-abraded, hydrofluoric acid, application of silica on the surface of ceramics with laser and conditioning Nd:YAG. Several authors agree that certainly with a combination of techniques sedimentary this process of union. ${ }^{2-5}$

With the constant evolution of the ceramic materials, their characteristics have been changed, since there are several ceramic compositions in the market. Thus, the hardness changes in accordance with the composition of ceramics and ceramic material for each, there is a protocol for surface conditioning. ${ }^{6}$

The aim of this study was to evaluate the effect of different types of surface treatments (hydrofluoric acid, hydrofluoric acid associated with the airborne particleabraded, CoJet system and Nd:YAG laser) in the roughness and surface of the different ceramic systems.

\section{MATERIALS AND METHODS}

The stainless steel metal mold was used to prepare the samples with the dimensions of $50 \mathrm{~mm}$ height and $20 \mathrm{~mm}$ thickness, having in one of its surfaces with two holes $10 \mathrm{~mm}$ diameter and $2 \mathrm{~mm}$ height.

For the ceramic system IPS Empress II on the hole in the metal matrix, was made the waxing of wax tiles (Renfert, Germany) containing the dimensions mentioned above, this specific wax for subsequent injection of the ceramic coating.

The tiles were included in specific covering IPS Empress II and after it has taken booty, the set was then taken to the GDS equipment, model EDGCON 3000 . Beside the coating, were also placed in the oven the ceramic tile and piston until reaching a temperature of $850^{\circ} \mathrm{C}$ in which they remained for 40 minutes to eliminate the wax.

A temperature of $850^{\circ} \mathrm{C}$, the set was transferred to the ceramic press furnace Ivoclar IPS Empress, model 2.9. The ring surface was laid at a temperature of $700^{\circ} \mathrm{C}$, raised to $920^{\circ} \mathrm{C}$ (melting temperature of the ceramic) $60^{\circ} \mathrm{C}$ per minute from the initial $700^{\circ} \mathrm{C}$. The temperature was kept at $920^{\circ} \mathrm{C}$ for 15 minutes before injection of the temperature ceramic coating were alike, the temperature remaining until the end of the injection of pottery which would be determined at the time that the piston was under pressure of 6 bars and time depended on the amount injected. After removal of the lining of the ring oven, porcelain was cooled to room temperature and open-jet coating of aluminum oxide particles $50 \mu \mathrm{m}$ to avoid damaging the material. The specimen also had the same dimensions as described above.

To prepare the specimens for the In-Ceram Alumina tiles were made of acrylic resin with stainless steel matrix so that later they were made in silicone matrix, the ease of work offered by the ceramic in its initial phase with this type material, in this case silicon.

Following the manufacturer's recommendations (VITA, 2000), were weighed 38 gm of powder of In-Ceram Alumina on a digital scale (Micronal B600, Micronal S/A, Sao Paulo, Brazil). In a glass beaker, was added to a ampoule of liquid mixing Vita In-Ceram Alumina/Zirconia $(5 \mathrm{ml})$ to a drop of additive Vita In-Ceram Alumina. In order to homogenize the liquid, this mixture was taken to the ultrasound machine (Vitasonic II-Vita Zahnfabrik, Germany) for 1 minute. After mixed with the alumina powder gradually with the aid of a glass spatula, stopping this process three times so that the container was taken for 2 minutes, the ultrasound device (Vitasonic II-Vita), in which there was ice cubes. After adding all the dust, the mixture remained for 7 minutes in an ultrasound machine to promote the complete homogenization of the material.

The material was mixed with small amount of slip, the name given to the suspension of alumina oxide, with distilled water in a pot dappen and with a fine tip brush, moisten the matrix to break the surface tension and prevent blisters occurred after the prey of the material. The slip was applied, with the help of brush in the silicone matrix. He waited for 2 hours at room temperature for drying the mixture occurred slip, allowing the removal of the bottom of the specimens silicone matrix, which have been kiln dried Inceramat 2 (Zahnfabrick Vita, Germany) for sintering, following the cycle recommended by the manufacturer.

In-Ceram Alumina has lanthanum glass powder specifically for their use. The glass powder of fine particles was mixed with distilled water to obtain a mass of fluid consistency. With the help of brush, was applied a layer about $2 \mathrm{~mm}$ thick in the entire length of the sintered bases, leaving a clear glass in one of the bases to allow the escape of air within the structure, since infiltration of the glass occurs by a process of capillary action, through the interior of the pore structure.

For the infiltration of the glass, the cycles were performed on slides of platinum-gold (CNG, Brazil), whose membership consisted of $95 \%$ platinum and $5 \%$ gold, with dimensions of $60 \times 50 \mathrm{~mm}$ and $0.1 \mathrm{~mm}$ thick, being the foundation, which will undergo surface treatment, arranged on the plate of platinum-gold with the opposite side facing up. In the oven, Inceramat 2 (Zahnfabrick Vita, Germany) was performed the cycle of infiltration glass of In-Ceram Alumina also according to the manufacturer's recommendations. Then, excess glass from the specimens was removed with a stream of aluminum oxide of $50 \mu \mathrm{m}$ and 3 bars pressure. 
After making specimens, they were randomly assigned to different types of surface treatment:

- Group T0: No treatment was applied, and thus this group served as a control.

- Group T1: Hydrofluoric acid-etched. Etching with hydrofluoric acid to $10 \%$ by the time of 1 minute and then, were washed thoroughly with water to neutralize the acidic effect.

- Group T2: Association of the conditioning of $10 \%$ hydrofluoric acid with airborne particle-abraded. Sandblasting with aluminum oxide particular with equipment manufactured by Bio-Art. Fifty micrometer particles blasted were used for 20 seconds, a distance of $1.0 \mathrm{~cm}$ and pressure of $120 \mathrm{psi}$.

- Group T3: Coverage of silica. The tiles were placed on a platform in which the jet of silica (Micro-Etcher, Inc Danville, San Ramon, CA, USA) was positioned at a distance of $1 \mathrm{~cm}$ (device developed by the discipline of Prosthodontics, UNESP, São José dos fields) at a pressure of 2.8 bar for 20 seconds with CoJet-Sand (silica particles are $30 \mu \mathrm{m}, 3 \mathrm{M}-\mathrm{ESPE}$, Minnesota, USA). These specimens were moved on the platform in order to obtain a homogeneous treatment.

- Group T4: Nd:YAG Laser Irradiation. Tests of laser beam irradiation were all performed in an equipment Digilaser 100-Violin 10-Nd:YAG ADITEK company, located in the city of Cravinhos (SP). The specimens were placed one by one on a metal plate on the tip of the laser action, individually and surface treatment with the laser in the specimens was performed. Computer was selected in the perimeter of the laser $\left(1 \mathrm{~cm}^{2}\right)$ the sweep speed $(100 \mathrm{~mm} / \mathrm{s})$, frequency $(35$ $\mathrm{kHz}$ ) and the laser power (100\% capacity).

Hundred samples were fabricated, 50 for each material. There were four readings on the surface roughness of the specimens, the two transverse and two longitudinal and five photos were taken of the surface of a specimens for each experimental condition, these randomly selected samples.

\section{RESULTS}

\section{Roughness}

Table 1 presents the mean and standard deviation of roughness values (averages of four readings) obtained on samples of In-Ceram Alumina (C1) and IPS Empress II (C2) subjected to surface treatments: hydrofluoric acid (T1); hydrofluoric acid associated with the airborne particle-abraded (T2); CoJet System (T3), Nd:YAG laser (T4) and untreated (T0: control).

Therefore, they should be considered for the analysis of the results of roughness: a statistical analysis with recommended care, the plots of means with confidence intervals and also the relevance of the differences found in practice. Therefore, it is evident that the means of groups with ceramics and intermediate $\mathrm{C} 1$ are close in relation to the control of $\mathrm{C} 2$ and $\mathrm{C} 2$ with the other groups. The average roughness of the ceramic $\mathrm{C} 2$ control group is the smallest of all, while the average T4 C2 is the greatest.

The variability of some different experimental groups compared with the change of control, show that the treatments affect the surface structure of the ceramics, although they may keep the same average roughness or increase them.

\section{Scanning Electron Microscopy}

The results obtained in the two photomicrographs are from indirect restorative materials with four treatments over the control surface. For the evaluation, were obtained in scanning electron microscopy photomicrographs 50 , five photomicrographs for each experimental condition. So, was chosen the photomicrograph to that showed the most valued characteristics of the condition.

\section{DISCUSSION}

To have success in esthetic and functional restorative dentistry when used indirect ceramic restorations is necessary that we have the adhesion between this material and the dental substrate, so that there are many requirements and care should be taken, since the preparation of the tooth to the cementation of indirect restorations. ${ }^{7,8}$

The composition and procedure used to obtain the small retentions ceramics are important components for further adhesion. ${ }^{1}$ In general, the indirect esthetic materials also have different levels of roughness and adhesion when subjected to superficial treatments. ${ }^{1,9-14}$ These are according to our results shown in Table 1 , which indicates that the effects of surface treatments depend on the composition and microstructure of ceramics.

In fact, there are several ways to improve retention and bond strength of esthetic restorative materials to

Table 1: Mean and standard deviation of roughness

\begin{tabular}{|c|c|c|c|c|}
\hline \multirow[b]{3}{*}{ Treatment } & \multicolumn{4}{|c|}{ Ceramic } \\
\hline & \multicolumn{2}{|c|}{ C1 } & \multicolumn{2}{|c|}{ C2 } \\
\hline & Mean & $\begin{array}{l}\text { Standard } \\
\text { deviation }\end{array}$ & Mean & $\begin{array}{l}\text { Standard } \\
\text { deviation }\end{array}$ \\
\hline T0 & $0.829^{b}$ & \pm 0.046 & $0.449^{a}$ & \pm 0.022 \\
\hline $\mathrm{T} 1$ & $0.928^{b c}$ & \pm 0.136 & $1.726^{\mathrm{e}}$ & \pm 0.143 \\
\hline T2 & $1.021^{b c}$ & \pm 0.125 & $1.527^{\mathrm{de}}$ & \pm 0.083 \\
\hline T3 & $1.046^{c}$ & \pm 0.083 & $1.493^{\mathrm{d}}$ & \pm 0.257 \\
\hline T4 & $0.876^{b c}$ & \pm 0.042 & $3.022^{f}$ & \pm 0.231 \\
\hline
\end{tabular}

Same letter means similarity between the mean values. Different letters mean difference in mean values 


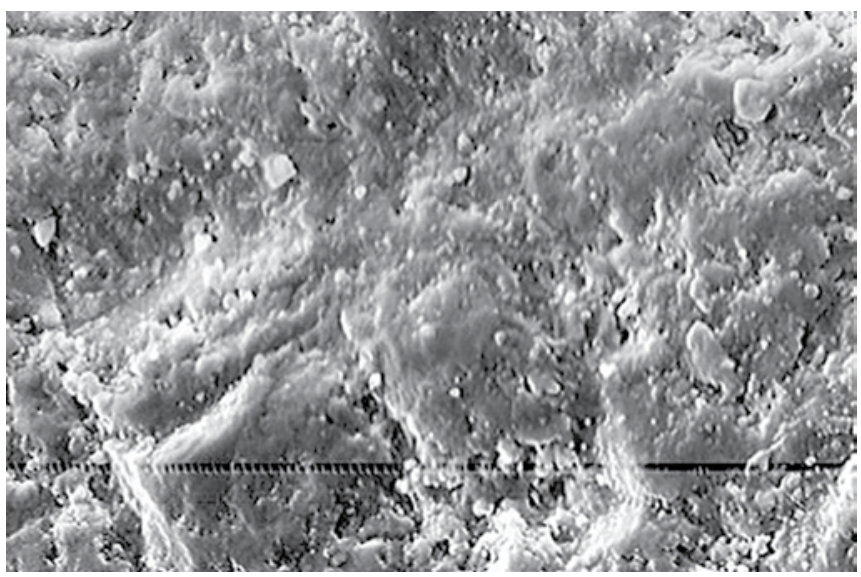

Fig. 1: The surface through quite regularly and particles dispersed in a ceramic matrix

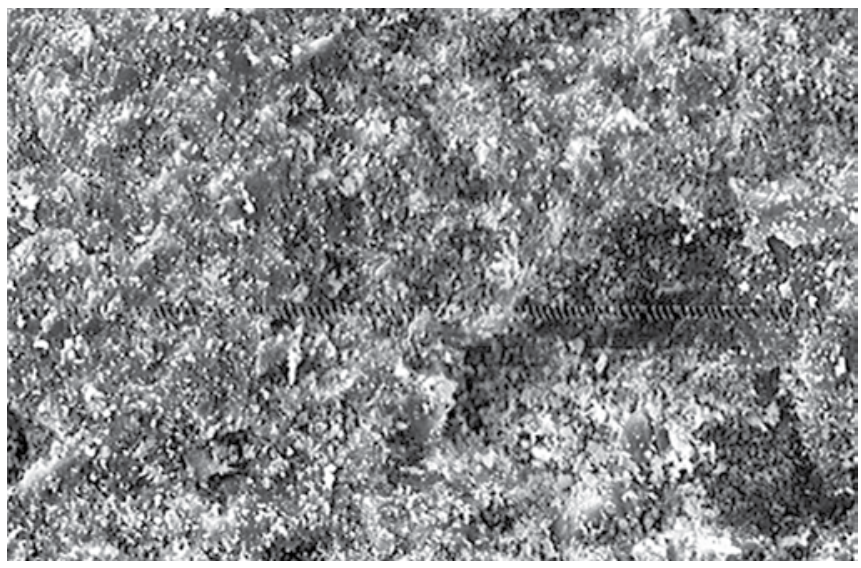

Fig. 3: This result is clear evidence that the appearance of small retentions on the surface of the material, as well as silica particles impregnated on the surface, characteristic of this type of treatment

tooth structure overhead. Obtaining small retentions by physical and chemical (Figs 1 and 2) has been investigated over the years and constitutes an important challenge to improve the clinical performance of these materials..$^{15}$ The main mechanical means to create microscopic retentions, the airborne particle-abraded and silica application through the system CoJet devices are considered to be extremely efficient in this regard (Figs 6 and 8), morphological changes arise because the surface of the ceramics of about $15 \mu \mathrm{m}$ for speed particle impact with the surface of the ceramic material. ${ }^{16-21}$ Thus, corroborate these claims somewhat with our findings by scanning electron microscopy, where Figures 3 and 7 show the features are highly suggestive small retentions surfaces of these materials.

Important device for small retentions is also the application of chemicals, such as hydrofluoric acid (Fig. 4), which acts on the surface of the ceramic glass dissolving the party and creating, thus, microporosity undercut by the exposure of areas of crystals that form the crystal..$^{22}$ These statements can be observed in Figure 9, where it is noticed the presence filamentous highly uniform surface with small crystals of lithium disilicate,

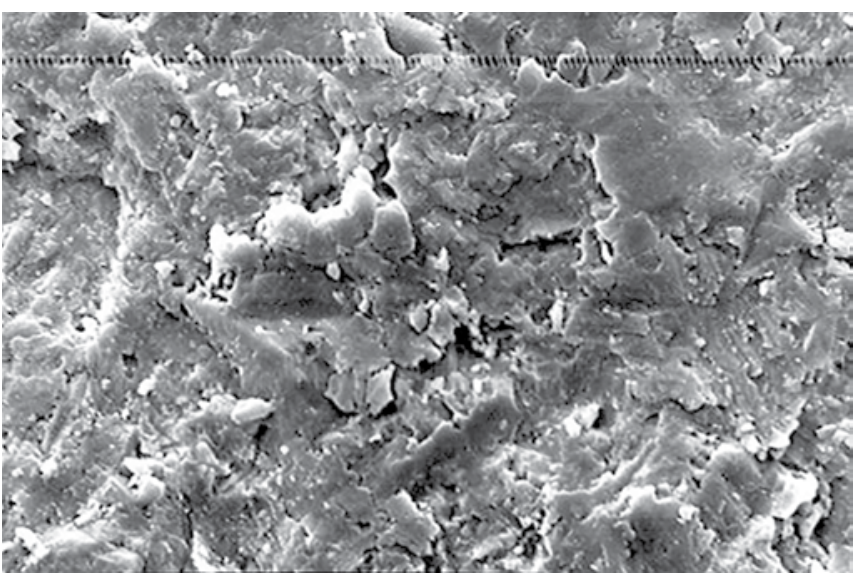

Fig. 2: The features in this photomicrograph show irregularities from the treatments to which this experimental group was submitted compared control

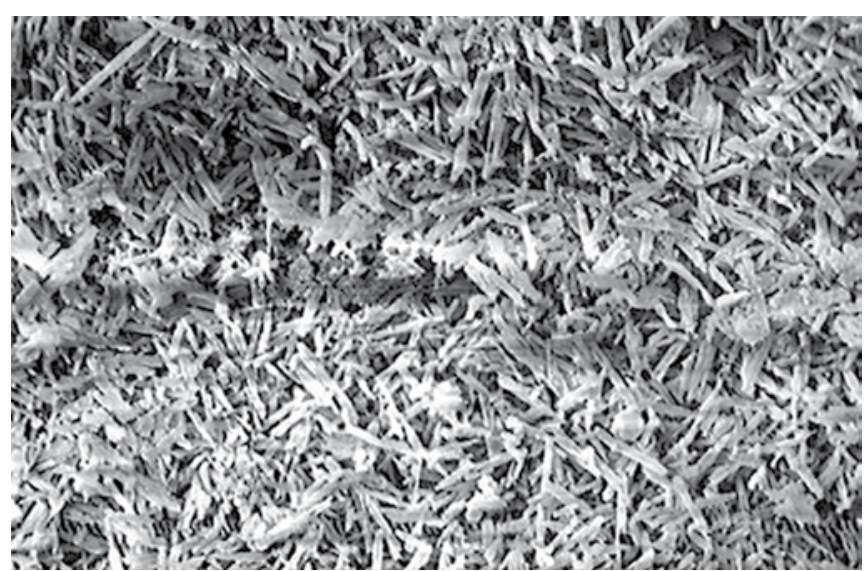

Fig. 4: Appearance of some microporosity, however, lead to a favorable surface for retention. In text shows as unfavorable

small retentions becoming apparent in the treated surface of the specimen. The composition of silica IPS Empress II is approximately $60 \%$ according to the manufacturer and is sufficient to obtain good bond with the resin cement without needing the technical coverage of silica.

Among the median, as the application of $\mathrm{CO}_{2}$ laser, $\mathrm{Nd}$ :YAG and Er,Cr:YAG was aimed at obtaining small retentions on the surface of ceramics. The authors stated that laser irradiation promotes adequate bond strength

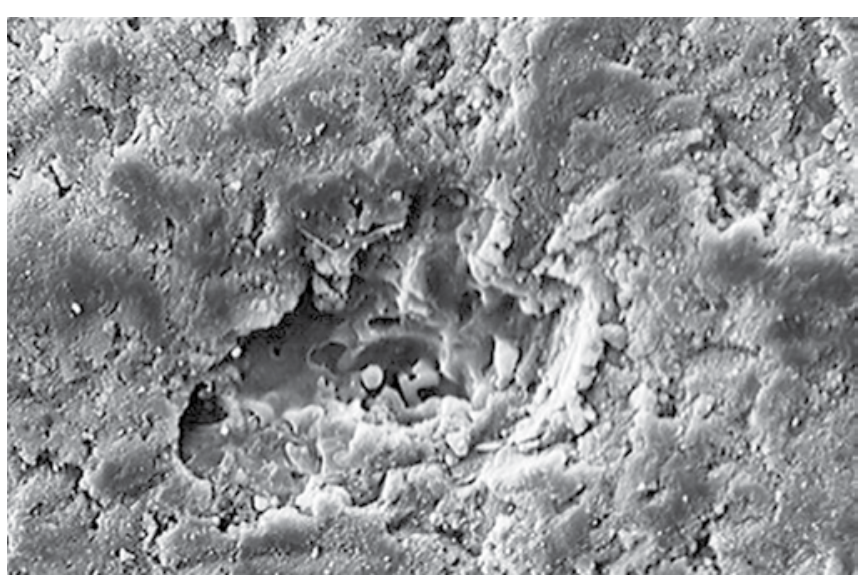

Fig. 5: Large retentions are observed (crater) in comparison with other treatments, as well as ceramic particles dispersed 


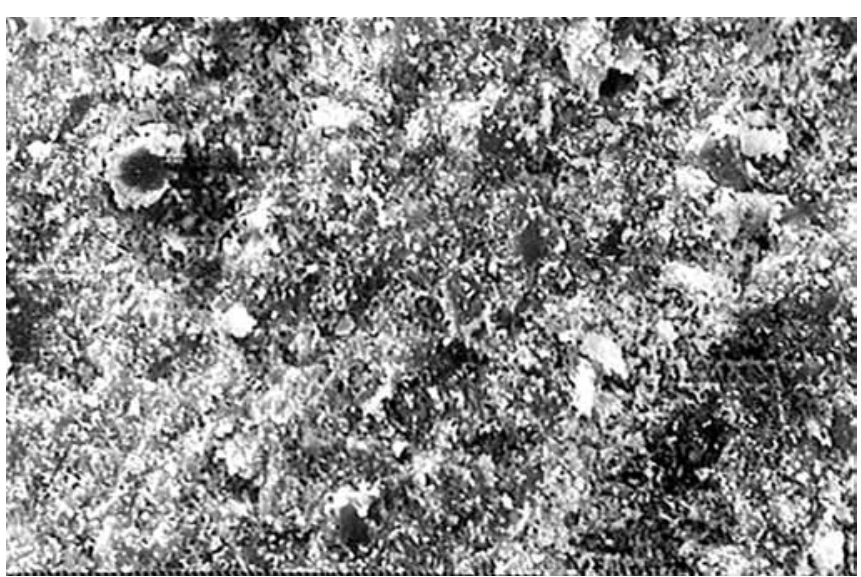

Fig. 6: It can be seen in this photomicrograph, a smooth surface partially disilicato lithium showing through the presence of crystals

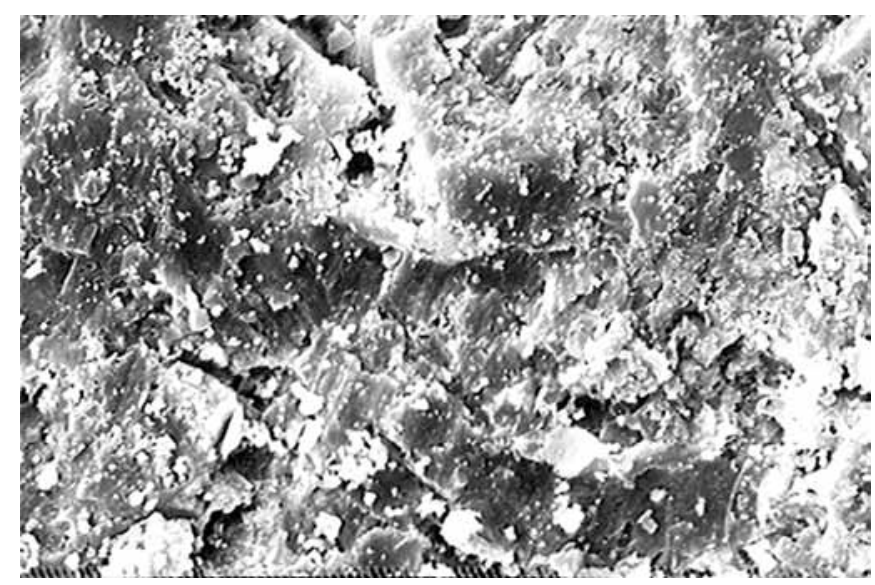

Fig. 8: Revealed the presence of erosions in the ceramic surface, silica particles from the treatment and also disilicato lithium particles dispersed on the surface without the presence of small retentions

at the surface of porcelain and can replace conventional methods, but further studies should be conducted to improve the technical and cost reduction. ${ }^{20,23,24}$ In our study, the laser Nd:YAG laser was tested on the following experimental conditions; In-Ceram alumina and IPS Empress II (Figs 5 and 10 respectively) where by such treatment showed a highly irregular surface, without providing an adequate holding pattern.

Over the years, with technological development and research for the professional interests have increased the possibilities of treatments for ceramic surfaces, as quoted in the preceding paragraphs, in order to improve and greater clinical success of ceramic restorations in cementations. According to Soares et $\mathrm{al}_{1}{ }^{25}$ the treatment of inner surfaces of the ceramic will depend on the composition of the material, the use of conditioning techniques and surface abrasion. Consequently, the clinician should know the full restorative materials and specific protocols to optimize the success of indirect restorative procedures.

Regarding the roughness, the variability of some different experimental groups compared with the change

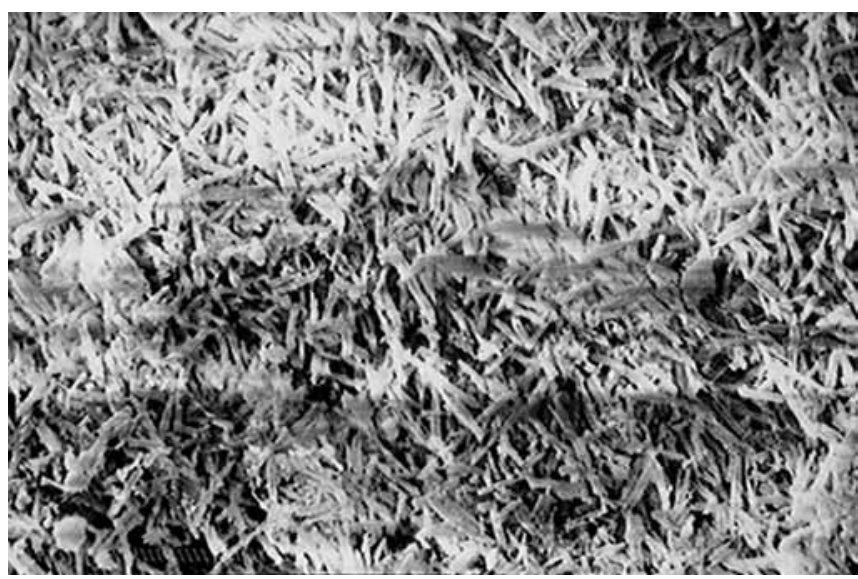

Fig. 7: This photomicrograph shows good exposure disilicato lithium crystals with filaments, causing the appearance of favoring small retentions

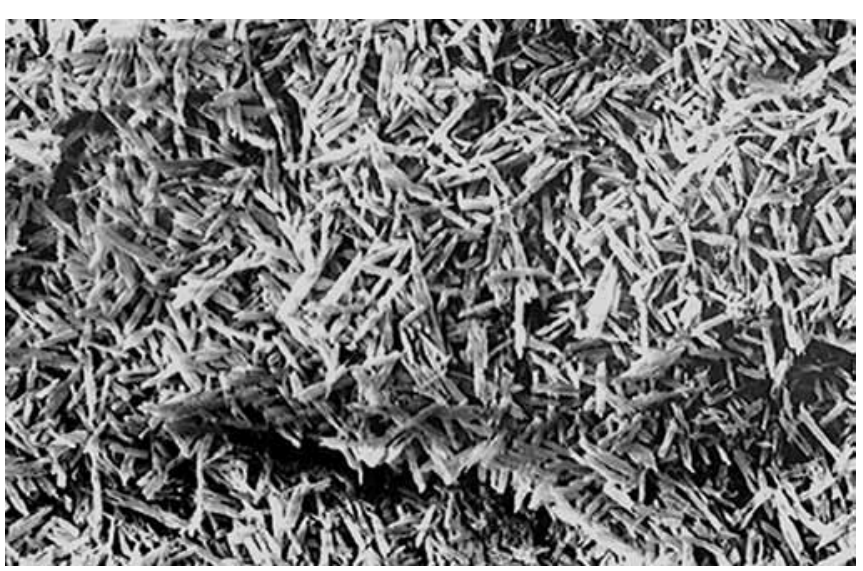

Fig. 9: Note the presence of highly uniform surface with small crystals of filamentous disilicato lithium small retentions being apparent in the specimen. The etching solution dissolves the thin layer of glass phase and exposes crystals disilicato lithium (both serve as retention qualities). The composition of silica IPS Empress II is approximately $60 \%$, according to the manufacturer, and is sufficient to obtain good bond with the resin cement without the technical coverage of silica

of control, show that the treatments affect the surface structure of the ceramics, although they may keep the same average roughness or increase them, this means that even that are highly rough surfaces, if this surface

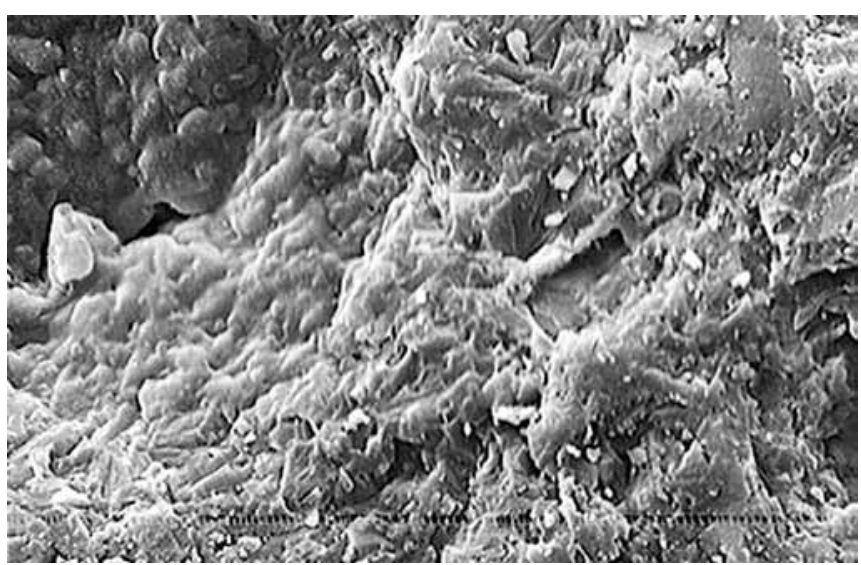

Fig. 10: This treatment has shown highly irregular surface without, however, provide uniformity favoring the retention retentive 
does not have a roughness standard or may not undergo an appropriate treatment process of the accession process may fail to commit to fixing the piece.

Thurmond et $\mathrm{al}^{26}$ indicated that the combination of airborne particle-abraded with hydrofluoric acid to $8 \%$ proved to have the best adhesion strength compared to those treatments carried out individually. Madani et $\mathrm{al}^{27}$ showed that treatment with airborne particleabraded to In-Ceram was more effective in producing the bond strength between composite and ceramic material when compared to the use of hydrofluoric acid at a concentration of $10 \%$. However, for the same material, the use of hydrofluoric acid to $5 \%$ showed values similar to those of airborne particle-abraded in bond strength. The results we found, shows that the presence of $10 \%$ hydrofluoric acid to the surface provided with an exposure of filamentous crystals, possibly suitable for improving retention. On the other hand, hydrofluoric acid to $10 \%$ did not cause significant changes in In-Ceram Alumina porcelain, probably due to its high resistance to chemical attack. How best to treat the ceramic surface for our results showed that conditioning with CoJet System where it is clear small retention the appearance of the surface of the material, as well as silica particles impregnated on the surface, characteristic of this type of treatment, suggesting high quality in bond strength.

The literature shows a lot of technical information about the mechanisms that aimed to increase the bond strength between porcelain and tooth structure. Among them, we can mention the application of the airborne particle-abraded, hydrofluoric acid and, more modernly, implementation of new systems with the use of laser beams, and impregnation of silica in the context of technical or Rocatec CoJet. In spite of all these attempts, the literature shows they are all effective in promoting an increase in roughness, but it should be noted that the irregularities they promoted in surface systems are ceramic or not conducive to good retention.

\section{CONCLUSION}

\section{Roughness}

- The means employed in the physical and chemical surface treatment of porcelain were able to cause small retention;

- IPS Empress II system showed higher values of roughness when subjected to a $10 \%$ hydrofluoric acid, followed by T2 and T3;

- For all treatments, levels of roughness were lower for the system In-Ceram Alumina;

- IPS Empress II system was more favorable toward the formation of small retention compared to In-Ceram Alumina.

\section{Scanning Electron Microscopy}

- The conditioning laser large retention provided on the surfaces of the ceramics tested;

- The system In-Ceram Alumina showed the appearance of small retention when using the system CoJet;

- The airborne particle-abraded small retention provided in all ceramic systems.

\section{REFERENCES}

1. Borges GA, Sophr AM, de Goes MF, Sobrinho LC, Chan DC. Effect of etching and airborne particle abrasion on the microstructure of different dental ceramics. J Prosthet Dent 2003 May;89(5):479-488.

2. Tonetto MR, Bandeca MC, Borges AH, Pinto SCS, Saad JRC, Campos EAD, Neto SDTP, De Andrade MF. Effects of Er,Cr:YSGG laser irradiation on external adaptation of restorations in caries-affected cavities. Laser Phys Lett 2013 Sep;10(9):095601.

3. Chen JH, Matsumura H, Atsuta M. Effect of etchant, etching period, and silane priming on bond strength to porcelain of composite resin. Oper Dent 1998 Sep-Oct;23(5):250-257.

4. Chen JH, Matsumura H, Atsuta M. Effect of different etching periods on the bond strength of a composite resin to a machinable porcelain. J Dent 1998 Jan;26(1):53-58.

5. Jardel V, Degrange M, Picard B, Derrien G. Surface energy of etched ceramic. Int J Prosthodont 1999 Sep-Oct;12(5):415-418.

6. Rossato DM, Bandeca MC, Saade EG, Lizarelli RFZ, Bagnato VS, Saad JRC. Influence of Er:YAG laser on surface treatment of aged composite resin to repair restoration. Laser Phys 2009 Nov;19(11):2144-2149.

7. Ozcan M, Vallittu PK. Effect of surface conditioning methods on the bond strength of luting cement to ceramics. Dent Mater 2003 Dec;19(8):725-731.

8. Cavalcanti AN, Foxton RM, Watson TF, Oliveira MT, Giannini M, Marchi GM. Y-TZP ceramics: key concepts for clinical application. Oper Dent 2009 May-Jun;34(3):344-351.

9. Della Bona A1, Anusavice KJ, Mecholsky JJ Jr. Failure analysis of resin composite bonded to ceramic. Dent Mater 2003 Dec;19(8):693-699.

10. Saygili G, Sahmali S. Effect of ceramic surface treatment on the shear bond strengths of two resin luting agents to all-ceramic materials. J Oral Rehabil 2003 Jul;30(7):758-764.

11. Schmage P, Nergiz I, Herrmann W, Ozcan M. Influence of various surface-conditioning methods on the bond strength of metal brackets to ceramic surfaces. Am J Orthod Dentofacial Orthop 2003 May;123(5):540-546.

12. Tavarez RR, Firoozmand LM, Silva MB, Malheiros AS, Bandéca MC. Overlays or ceramic fragments for tooth restoration: an analysis of fracture resistance. J Contemp Dent Pract 2014 Jan 1;15(1):56-60.

13. Attia A, Kern M. Long-term resin bonding to zirconia ceramic with a new universal primer. J Prosthet Dent 2011 Nov;106(5):319-327.

14. Filho AM1, Vieira LC, Araújo E, Monteiro Júnior S. Effect of different ceramic surface treatments on resin microtensile bond strength. J Prosthodont 2004 Mar;13(1):28-35.

15. Foxton RM, Cavalcanti AN, Nakajima M, Pilecki P, Sherriff M, Melo L, Watson TF. Durability of resin cement bond to aluminium oxide and zirconia ceramics after air abrasion and laser treatment. J Prosthodont 2011 Feb;20(2):84-92. 
16. Türkmen C, Sazak H, Günday M. Effects of the Nd:YAG laser, air-abrasion, and acid-etchant on filling materials. J Oral Rehabil 2006 Jan;33(1):64-69.

17. Xible AA1, de Jesus Tavarez RR, de Araujo Cdos R, Bonachela WC. Effect of silica coating and silanization on flexural and composite-resin bond strengths of zirconia posts: An in vitro study. J Prosthet Dent 2006 Mar;95(3):224-249.

18. Kim BK, Bae HE, Shim JS, Lee KW. The influence of ceramic surface treatments on the tensile bond strength of composite resin to all-ceramic coping materials. J Prosthet Dent 2005 Oct;94(4):357-362.

19. Valandro LF1, Della Bona A, Antonio Bottino M, Neisser MP. The effect of ceramic surface treatment on bonding to densely sintered alumina ceramic. J Prosthet Dent 2005 Mar;93(3): 253-259.

20. Akova T, Yoldas O, Toroglu MS, Uysal H. Porcelain surface treatment by laser for bracket-porcelain bonding. Am J Orthod Dentofacial Orthop 2005 Nov;128(5):630-637.

21. Guazzato M1, Albakry M, Quach L, Swain MV. Influence of surface and heat treatments on the flexural strength of a glass-infiltrated alumina/zirconia-reinforced dental ceramic. Dent Mater 2005 May;21(5):454-463.
22. Azam Valian and Elham Moravej-Salehi. Surface treatment of feldspathic porcelain: scanning electron microscopy analysis. J Adv Prosthodont 2014 Oct; 6(5):387-394.

23. Quran FA, Haj-Ali R. Fracture strength of three all-ceramic systems: Top-Ceram compared with IPS-Empress and InCeram. J Contemp Dent Pract 2012 Mar 1;13(2):210-215.

24. Al-Wahadni AM, Hussey DL, Grey N, Hatamleh MM. Fracture resistance of aluminium oxide and lithium disilicatebased crowns using different luting cements: an in vitro study. J Contemp Dent Pract 2009 Mar 1;10(2):51-58.

25. Soares CJ, Soares PV, Pereira JC, Fonseca RB. Surface treatment protocols in the cementation process of ceramic and laboratory-processed composite restorations: a literature review. J Esthet Restor Dent 2005;17(4):224-35. Review.

26. Thurmond JW, Barkmeier WW, Wilwerding TM. Effect of porcelain surface treatments on bond strengths of composite resin bonded to porcelain. J Prosthet Dent 1994 Oct;72(4): 355-359.

27. Madani M1, Chu FC, McDonald AV, Smales RJ. Effects of surface treatments on shear bond strengths between a resin cement and an alumina core. J Prosthet Dent 2000 Jun;83(6): 644-647. 